16. Pagni CA, Ettorre G, Infuso L, Marossero F. EMG responses to capsular stimulation in the human. Experientia 1964;20:691-692.

17. Marsden CD, Merton PA, Morton HB. Is the human stretch reflex cortical rather than spinal? Lancet 1973;1:759-761.

18. Marsden CD, Hallett M, Fahn S. The nosology and pathophysiology of myoclonus. In: Marsden CD, Fahn S, eds. Movement disorders. London: Butterworths, 1982:196-248.

19. Lüders H, Lesser P, Dinner DS, Morris HH, Wyllie E, Godoy J. Localization of cortical function: new information from extraoperative monitoring of patients with epilepsy. Epilepsia 1988;29(suppl 2):S56-S65.

20. Gloor P. Generalized epilepsy with spike-and-wave discharge: a reinterpretation of its electrographic and clinical manifestations. Epilepsia 1979;20:571-588.

21. Matsuoka H, Okuma T, Ueno T, Saito H. Impairment of parietal cortical functions associated with episodic prolonged spike-and-wave discharges. Epilepsia 1986;27:432-436.
22. Aarts JHP, Binnie CD, Smit AM, Wilkins AJ, Selective cognitive impairment during focal and generalized epileptiform EEG activity. Brain 1984;107:293-308.

23. Shewmon DA, Erwin RJ. The effect of focal interictal spikes on perception and reaction time. I. General considerations. Electroencephalogr Clin Neurophysiol 1988;69:319-337.

24. Shewmon DA, Erwin RJ. The effect of focal interictal spikes on perception and reaction time. II. Neuroanatomic specificity. Electroencephalogr Clin Neurophysiol 1988;69:338-352.

25. Shewmon DA, Erwin RJ. Focal spike-induced cerebral dysfunction is related to the after-coming slow wave. Ann Neurol 1988;23:131-137.

26. Ugawa Y, Shimpo T, Mannen T. Physiological analysis of asterixis: silent period locked averaging. J Neurol Neurosurg Psychiatry 1989;52:89-93.

27. Artieda J, Muruzabal J, Larumbe R, Garcia de Casasola C Obeso JA. Cortical mechanisms mediating asterixis. Mov Disord 1992;7:209-216.

\title{
Early childhood prolonged febrile convulsions, atrophy and sclerosis of mesial structures, and temporal lobe epilepsy: An MRI volumetric study
}

F. Cendes, MD; F. Andermann, MD, FRCP(C); F. Dubeau, MD, FRCP(C); P. Gloor, MD, PhD; A. Evans, PhD; M. Jones-Gotman, PhD; A. Olivier, MD, PhD, FRCS(C); E. Andermann, MD, PhD; Y. Robitaille, MD; I. Lopes-Cendes, MD; T. Peters, PhD; and D. Melanson, MD

Article abstract-We performed MRI volumetric measurements of the amygdala (AM) and hippocampal formation (HF) in a group of 43 patients with temporal lobe epilepsy not controlled by optimal drug treatment. Fifteen patients (35\%) had a history of prolonged febrile convulsions (PFC) in early childhood; 30 patients underwent surgery, and histopathology was available in twenty-four. The mean values of AM and HF volumes ipsilateral to the EEG focus were significantly smaller than those of normal controls. The volumetric measurements showed a more pronounced atrophy of the AM in patients with a history of PFC, although the HF volumes were also smaller in this group. Patients with a history of PFC had a higher proportion of more severe mesial temporal sclerosis (MTS) compared with those with no PFC. These findings confirm a correlation between early childhood PFC, the severity of atrophy of mesial structures, and MTS.

NEUROLOGY 1993;43:1083-1087

Hippocampal sclerosis is frequent in temporal lobe epilepsy (TLE), as demonstrated at autopsy ${ }^{1,2}$ and in tissue resected at the time of surgical treatment. ${ }^{3-5}$ The etiology and pathogenesis of hippocampal sclerosis and its relationship to TLE has been a source of controversy over the last centu- ry. ${ }^{1,6}$ Hippocampal sclerosis may have several causes, but an association with a history of prolonged, usually febrile, early childhood convulsions is a common finding in TLE. ${ }^{1,7,8}$

MRI is currently the most effective method for detecting gross structural lesions in patients with

From the Department of Neurology and Neurosurgery, McGill University and the Montreal Neurological Hospital and Institute, Montreal, Quebec, Canada.

Received July 14, 1992. Accepted for publication in final from October 26, 1992.

Address correspondence and reprint requests to Dr. Frederick Andermann, Montreal Neurological Hospital and Institute, 3801 University St., Montreal, $\mathrm{PQ}$, Canada H3A 2B4. 
TLE. However, many candidates for surgical treatment of seizures have gliosis and neuronal loss in mesial temporal structures that cannot be seen clearly, even on preoperative high-resolution MRI. ${ }^{9-11}$

Quantitative MRI-based volume measurements of the hippocampus improve the detection of unilateral atrophy in patients with epilepsy. ${ }^{12-16}$ Since the amygdala (AM) plays an important role in the pathophysiology of TLE, it appeared reasonable to include measurements of this structure as well as that of the hippocampal formation (HF).,16-21

In the present study, we compared the results of volumetric measurements of the AM and HF and the histopathology in patients with TLE who had prolonged febrile convulsions (PFC) in early childhood with those of TLE patients without PFC.

Methods. Subjects. We performed MRI volumetric measurements of the AM and HF in a group of 43 patients (19 males and 24 females; mean age, 34.3 years) with TLE not controlled by optimal drug treatment. A clear EEG lateralization was available in 35 patients using surface and sphenoidal recordings. In eight, the lateralization was determined by depth electrode studies because of the ambiguity of the scalp EEG. The degree of lateralization was sufficiently clear to permit a surgical decision in all. Patients were not otherwise selected and represent a group admitted for investigation from June 1991 to August 1992.

The history of PFC was based on detailed accounts from parents and other relatives at the time of hospital admission as well as on a review of the patients' medical records of early childhood hospitalization. The 43 patients were divided into the following groups:

Group I. Fifteen patients with history of PFC in early childhood (35\%), with mean age of 29.4 years (range, 18 to $48 ; \mathrm{SD}=9,0$ ).

Group II. Twenty-eight patients with no history of PFC $(65 \%)$, with mean age of 36.9 years (range, 12 to 62 ; $\mathrm{SD}=10.0$ ).

We used a control group consisting of 13 healthy volunteers (eight men and five women), with mean age of 32.2 years (range, 20 to $50 ; \mathrm{SD}=11.3$ ), for comparison.

The characteristics of the patient groups are summarized in table 1 , and the controls in table 3 .

Thirty patients underwent either transcortical selective amygdalo-hippocampectomy or anterior temporal lobe resection including amygdala and anterior hippocampus. Since the surgical removals were done by subpial aspiration, the samples of mesial temporal structures available for pathologic examination were not optimal, but correlation of reduced volumes of AM and HF with pathologic findings was possible in 24 patients.

After excision, the tissue was fixed for 12 to 24 hours in $10 \%$ buffered formalin, then cut anteroposteriorly, embedded in paraffin, and sectioned. Staining was carried out using Cajal's gold chloride sublimate, Luxol fast blue, and hematoxylin-eosin.

We used the term "mesial temporal sclerosis" (MTS), as reviewed by Meencke and Veith, ${ }^{1}$ to include changes in the hippocampus, the adjacent entorhinal cortex, and the amygdala. The term "MTS" is used here as a qualitative and descriptive one. ${ }^{1,21}$ The pathologist was unaware of whether or not the patients had a history of PFC.

MRI acquisition. MRIs were obtained on a 1.5-tesla
Philips Gyroscan S15-HP unit. Thirty-two slices on coronal views, perpendicular to the lateral sulcus (Sylvian fissure), were obtained using a 3-D gradient fast field echo sequence with 3-mm contiguous sections, a 75/16/2 (TR/TE/number of signal averages) pulse sequence, a matrix size of $256 \times 256$, with a $250-\mathrm{mm}$ field of view and a $60^{\circ}$ flip angle.

Volumetric analysis. The images were transferred to a Sun SPARC work station (Sun Microsystems, Mountain View, CA). Volumetric measurements were performed with an interactive software program developed at the Neuroimaging Laboratory of the Montreal Neurological Institute. The regions of interest were outlined using a manual contouring editing function. Once the outline had been defined, the slice volume was calculated automatically by the computer program. A detailed description of the protocol and the anatomic landmarks used in the present work has been given by Watson et al. ${ }^{17}$

Volumes of AM and HF were obtained on each patient and compared with values from the normal control group. Another measure to determine the degree of asymmetry between sides was established by using the right minus left side difference $(\mathrm{R}-\mathrm{L})$. This method was utilized by others ${ }^{12-14}$ to assess asymmetry of the HF.

Four AM measurements were excluded due to MRI artifacts present in this region.

Statistical analysis. We defined significant smallness of $\mathrm{AM}$ and $\mathrm{HF}$ as values below $2 \mathrm{SD}$ of the respective mean values of the normal control group. The side asymmetry expressed by $R-L A M$ and $R-L$ HF was considered significant when 2 SD above the mean of control group. The volume measurements were expressed in cubic millimeters.

We performed an analysis of variance (ANOVA) comparing the $\mathrm{AM}$ and $\mathrm{HF}$ volumetric measurements from all three groups: patients with PFC (group I), patients without antecedent of PFC (group II), and normal controls. We then used a planned comparison with two orthogonal comparisons: (1) PFC patients (group I) versus patients without PFC (group II); (2) normal controls versus all patients (group I plus group II). The same statistical approach was used to analyze the amount of asymmetry between sides (R-L) for AM and HF volumes.

We used Fisher's exact test to compare the pathologic categories in each of the two groups. This analysis was based on the classification given independently by the pathologist as mild, moderate, or severe degree of MTS.

We compared the age ( $t$ test) of both groups of patients.

We considered statistical significance to be present at $p<0.05$.

Results. The volumetric measurements of patients and controls are summarized in tables 1 to 3 .

The ANOVA showed a significant difference among the three groups for AM ( $\mathrm{F}=22.5, p<0.0001)$ and $\mathrm{HF}$ volumes $(\mathrm{F}=14.1, p<0.0001)$. The orthogonal comparison showed a significant difference between the two groups of patients, with $\mathrm{AM}$ and $\mathrm{HF}$ volumes being smaller in group I (patients with PFC) $(\mathrm{F}=15.7, p<0.001 ; \mathrm{F}=6.4, p<0.02$, respectively). The second orthogonal comparison showed that AM and HF volumes of patients (group I plus group II) were significantly smaller than controls (F $=8.9, p<0.005 ; \mathrm{F}=21.0, p<0.001$, respectively). 
Table 1. Summary of data from both groups of patients

\begin{tabular}{|c|c|c|c|c|c|c|c|c|c|}
\hline Pt no. & Age & Sex & PFC & Classif. & R. HF & L. HF & R. AM & L. AM & Pathology \\
\hline 1 & 39 & $\mathbf{F}$ & Yes, 6 y & L. TLE & 4348.1 & 4259.9 & 3096.6 & 2749.2 & MTS severe $(+\mathrm{AM})$ \\
\hline 2 & 29 & $\mathbf{F}$ & Yes, $10 \mathrm{mo}$ & L. TLE & 4377.8 & 3228.3 & 2124.9 & 1677.6 & MTS moderate (+AM) \\
\hline 3 & 23 & $\mathbf{M}$ & Yes, 1 y & R. TLE & 3509.4 & 4575.7 & 2681.8 & 3014.3 & MTS moderate \\
\hline 4 & 36 & $\mathbf{M}$ & Yes, $10 \mathrm{mo}$ & L. TLE & 4555.2 & 4004.2 & 2124 & 1906.9 & MTS severe \\
\hline 5 & 18 & $F$ & Yes, 9 mo & L. TLE & 4087.6 & 3782.5 & 2247.7 & 2026.9 & MTS mild \\
\hline 6 & 24 & $\mathbf{F}$ & Yes, 9 mo & L. TLE & 5453.5 & 3433.5 & 2796.5 & 2428.8 & MTS moderate \\
\hline 7 & 22 & $\mathbf{M}$ & Yes, $7 \mathrm{mo}$ & L. TLE & 4466.9 & 3470 & 2942.8 & 2345.5 & - \\
\hline 8 & 37 & $\mathbf{F}$ & Yes, $6 \mathrm{mo}$ & R. TLE & 2549.1 & 3450.9 & 1573.7 & 2145.9 & - \\
\hline 9 & 48 & $\mathbf{F}$ & Yes, 6 mo & L. TLE & 4347 & 2208.9 & 2535.7 & 1701.1 & MTS moderate \\
\hline 10 & 23 & $F$ & Yes, $5 \mathrm{mo}$ & L. TLE & 4142.9 & 3613.7 & 2506.2 & 1989.4 & M'TS moderate \\
\hline 11 & 44 & $\mathbf{M}$ & Yes, 1 y & R. TLE & 3433.2 & 4179.2 & 2217.9 & 2895.7 & MTS severe \\
\hline 12 & 31 & $\mathbf{F}$ & Yes, 7 mo & L. TLE & 5475.1 & 3688.6 & 3068.5 & 2429.7 & MTS severe \\
\hline 13 & 26 & $\mathbf{F}$ & Yes, $8 \mathrm{mo}$ & L. TLE & 4997.2 & 3272.3 & 2409.7 & 1615.2 & - \\
\hline 14 & 19 & $\mathbf{M}$ & Yes, 2 y & R. TLE & 3534.5 & 4925 & 2078.1 & 2412 & - \\
\hline 15 & 22 & $\mathbf{M}$ & Yes, 6 mo & L. TLE & 3600.9 & 2787.9 & 2587.5 & 2183.6 & - \\
\hline 16 & 35 & $\mathbf{M}$ & No & L. TLE & 4251.9 & 3066.8 & 2917.2 & 2259.5 & MTS moderate \\
\hline 17 & 62 & $\mathbf{F}$ & No & L. TLE & 5033.8 & 3576.6 & 2429.9 & 2324.2 & - \\
\hline 18 & 42 & M & No & L. TLE & 4795.6 & 5106.6 & 2875.4 & 2929.3 & MTS moderate \\
\hline 19 & 27 & $\mathrm{~F}$ & No & L. TLE & 4599.1 & 3355.2 & 3290.6 & 2878.5 & - \\
\hline 20 & 38 & $\mathbf{M}$ & No & L. TLE & 5369.4 & 3674.7 & - & - & MTS moderate \\
\hline 21 & 49 & $\mathbf{M}$ & No & L. TLE & 4556.2 & 3402 & 3193.4 & 2177.1 & - \\
\hline 22 & 33 & $\mathbf{F}$ & No & R. TLE & 4447.4 & 4853.2 & 3136.6 & 3171.7 & - \\
\hline 23 & 30 & $\mathbf{M}$ & No & R. TLE & 4115.2 & 4599.8 & 3065.3 & 3325.9 & - \\
\hline 24 & 38 & $\mathbf{F}$ & No & R. TLE & 2974.5 & 4656.3 & - & - & - \\
\hline 25 & 33 & $\mathbf{F}$ & No & R. TLE & 2119.1 & 3131.4 & - & - & MTS mild \\
\hline 26 & 48 & $\mathbf{M}$ & No & R. TLE & 4072.8 & 4818 & 2219.5 & 3134.7 & - \\
\hline 27 & 39 & $\mathbf{F}$ & No & R. TLE & 4760.7 & 4554.3 & 3161.9 & 3149.9 & - \\
\hline 28 & 48 & F & No & R. TLE & 3564.1 & 3948.9 & 2010.5 & 2208.2 & MTS mild \\
\hline 29 & 30 & $\mathrm{~F}$ & No & R. TLE & 5175.9 & 5362.3 & 3041.8 & 3336.5 & - \\
\hline 30 & 22 & $\mathbf{F}$ & No & R. TLE & 3707.2 & 4204.8 & 2130.8 & 2310.4 & MTS moderate \\
\hline 31 & 37 & $\mathrm{~F}$ & No & L. TLE & 4090.5 & 3817.2 & 3638.9 & 3587.6 & MTS severe \\
\hline 32 & 56 & $\mathbf{M}$ & No & L. TLE & 4537.3 & 4191.5 & 2297.7 & 2210.5 & - \\
\hline 33 & 35 & $\mathbf{M}$ & No & L. TLE & 4427.5 & 4480 & 2545.9 & 2597.3 & MTS mild \\
\hline 34 & 26 & $\mathbf{M}$ & No & L. TLE & 5076.9 & 4250.4 & 3145.7 & 2909.5 & MTS mild \\
\hline 35 & 38 & $\mathbf{M}$ & No & L. TLE & 4988.8 & 4543.5 & 2426.4 & 2305.8 & MTS moderate \\
\hline 36 & 34 & $\mathrm{~F}$ & No & L. TLE & 4755.2 & 4525.7 & 2724.7 & 2506 & - \\
\hline 37 & 12 & $\mathbf{M}$ & No & R. TLE & 2900.4 & 4399.8 & 2805.4 & 3049.7 & MTS severe (+AM) \\
\hline 38 & 34 & $F$ & No & L. TLE & 4329 & 2832.3 & 2859.1 & 2206.7 & MTS mild \\
\hline 39 & 45 & $\mathbf{F}$ & No & L. TLE & 4700.9 & 4185.9 & 3305.6 & 2616.2 & - \\
\hline 40 & 35 & $\mathrm{~F}$ & No & L. TLE & 5132.7 & 4703.5 & 2587.3 & 2271.8 & - \\
\hline 41 & 31 & $\mathbf{M}$ & No & L. TLE & 4498.2 & 3666.7 & 2628.1 & 2280.8 & - \\
\hline 42 & 45 & $\mathbf{M}$ & No & L. TLE & 4801.7 & 4293.3 & 3449 & 3175.9 & MTS mild \\
\hline 43 & 33 & $\mathbf{F}$ & No & L. TLE & 3969 & 3088.6 & - & - & MTS mild \\
\hline \multicolumn{10}{|c|}{$\begin{array}{l}\text { Classif. = patients were classified as right temporal lobe epilepsy (R. TLE) or left temporal lobe epilepsy (L. TLE) according to the results of ictal } \\
\text { and interictal EEG findings. }\end{array}$} \\
\hline \multicolumn{10}{|c|}{$\begin{array}{l}\text { PFC = history of prolonged febrile convulsions in early childhood. The numbers denote the age at which these occurred or of the first episode when } \\
\text { there was more than one. }\end{array}$} \\
\hline \multicolumn{10}{|c|}{ R. AM, L. AM, R. HF, and L. HF represent, respectively, the right and left amygdala and right and left hippocampal formation volumes in mm ${ }^{3}$. } \\
\hline
\end{tabular}

The ANOVA showed that the amounts of asymmetry between sides $(\mathrm{R}-\mathrm{L})$ for $\mathrm{AM}$ and $\mathrm{HF}$ were statistically different among the three groups $(\mathrm{F}=$ $10.0, p<0.0001 ; \mathrm{F}=13.9, p<0.0001$, respectively). The first orthogonal comparison showed a significant difference between the two groups of patients, with more pronounced AM and HF asymmetry in group I (patients with $\mathrm{PFC})(\mathrm{F}=5.9, p<0.02 ; \mathrm{F}=$ 4. $6, p<0.05$, respectively). The second orthogonal comparison showed that the amount of side asym- metry for AM and HF was significantly more pronounced in the patients (group I plus group II) than in the controls $(\mathrm{F}=14.1, p<0.001 ; \mathrm{F}=23.1, p$ $<0.001$, respectively).

Combining the AM and HF measurements, we found a significant asymmetry (with reduced volume on the side of EEG focus) in all patients of group I and in $85 \%$ of group II.

In 30 patients who underwent surgery, specimens of mesial temporal structures available for 
correlation between the occurrence of $\mathrm{PFC}$ in infancy and the degree of MTS. $1,4,5,8$ We did not find a correlation between the total duration of epilepsy and the severity of MTS. ${ }^{23}$ Our data showed that patients with early convulsions, who had MRI volumetric studies in early adolescence, had greater atrophy than those whose epilepsy was of longer duration but who did not have convulsions in early life. This does not rule out the possibility that repeated seizures over a longer period may produce additional, more subtle, hippocampal damage, of the kind described by Mouritzen Dam. ${ }^{2}$

In a previous series from our institution, we found a higher frequency of gestational or birth complications (mostly minor) in TLE patients who had had prolonged febrile convulsions. This suggests that such perinatal or other preexisting factors may make it more likely for a febrile convulsion to be prolonged or complex in children who have a genetic predisposition for febrile convulsions. Such perinatal or preexisting factors, in themselves, may not be sufficient to produce TLE, but the prolonged and often lateralized febrile convulsion leads to hippocampal sclerosis and focal temporal epileptogenicity (Abou-Khalil et al, in preparation).

Patients with TLE preceded by PFC represent a distinctive group. They have fairly homogeneous clinical and pathologic characteristics and constitute $35 \%$ to $40 \%$ of the patients undergoing surgical treatment for TLE at the Montreal Neurological Hospital. A history of PFC in infancy allows one to predict the likelihood of a good surgical outcome (Abou-Khalil et al, in preparation).

The smallness and pathologic abnormality of the AM may identify a subgroup among patients with mesial sclerosis causing TLE. ${ }^{24}$ This may explain the effectiveness, in some patients, of corticoamygdalectomy with minimal or no hippocampal resection. ${ }^{19}$ Recognition and quantification of these atrophic changes may be important in planning treatment for patients in whom resection of the hippocampus is not safe because of severe memory impairment.

Further studies are required to establish the relative importance of unilateral or bilateral atrophy of the amygdala, the hippocampus, or both, compared with the EEG, neuropsychological studies, and functional neuroimaging. This may lead to a more rational and less invasive approach to the treatment of TLE.

\section{Acknowledgments}

The authors thank Mrs. R. Amsel for reviewing the statistical analysis of the manuscript.

\section{References}

1. Meencke HJ, Veith G. Hippocampal sclerosis in epilepsy. In:
Lüders HO, ed. Epilepsy surgery. New York: Raven Press, 1991:705-715.

2. Mouritzen Dam A. Epilepsy and neuron loss in the hippocampus. Epilepsia 1980;21:617-629.

3. Falconer MA, Serafetinides EA, Corselis JAN. Etiology and pathogenesis of temporal lobe epilepsy. Arch Neurol 1964;10:233-248.

4. Babb TL, Brown WJ, Pretorius J, et al. Temporal lobe volumetric cell densities in temporal lobe epilepsy. Epilepsia 1984;25:729-740.

5. Babb TL. Research on the anatomy and pathology of epileptic tissue. In: Lüders HO, ed. Epilepsy surgery. New York: Raven Press, 1991:719-727.

6. Gloor P. Mesial temporal sclerosis: historical background and an overview from a modern perspective. In: Lüders $\mathrm{HO}$, ed. Epilepsy surgery. New York: Raven Press, 1991:689-703.

7. Bruton CJ. The neuropathology of temporal lobe epilepsy. New York: Oxford University Press, 1988.

8. Sagar HJ, Oxbury JM. Hippocampal neuron loss in temporal lobe epilepsy: correlation with early childhood convulsions. Ann Neurol 1987;22:334-340.

9. Berkovic SF, Andermann F, Olivier A, et al. Hippocampal sclerosis in temporal lobe epilepsy demonstrated by magnetic resonance imaging. Ann Neurol 1991;29:175-182.

10. Sperling MR, Wilson G, Engel J Jr, Babb TL, Phelps M, Bradley W. Magnetic resonance imaging in intractable partial epilepsy: correlative studies. Ann Neurol 1986;20:57-62.

11. Kuzniecky R, de la Sayette V, Ethier R, et al. Magnetic resonance imaging in temporal lobe epilepsy: pathological correlation. Ann Neurol 1987;22:341-347.

12. Cascino GD, Jack CR, Parisi JE, et al. Magnetic resonance imaging-based volume studies in temporal lobe epilepsy: pathological correlations. Ann Neurol 1991;30:31-36.

13. Jack CR, Sharbrough FW, Twomey CK, et al. Temporal lobe seizures: lateralization with MR volume measurements of the hippocampal formation. Radiology 1990;175:423-429.

14. Jack CR, Sharbrough FW, Cascino G, et al. Magnetic resonance image-based hippocampal volumetry: correlation with outcome after temporal lobectomy. Ann Neurol 1992;31:138146.

15. Lencz T, McCarthy G, Bronen R, Inserni J, Kim JH, Spencer DD. Hippocampus in temporal lobe epilepsy: correlation of presurgical MRI volumetrics with postsurgical cell counts [abstract]. Epilepsia 1990;31:667-668.

16. Cendes F, Andermann F, Gloor P, et al. MRI volumetric measurements of amygdala and hippocampus in temporal lobe epilepsy. Neurology 1993;43:719-725.

17. Watson C, Andermann F, Gloor P, et al. Anatomic basis of amygdaloid and hippocampal volume measurement by magnetic resonance imaging. Neurology 1992;42:1743-1750.

18. Feindel W, Robitaille Y, Tampieri D, Goossens L, Li M, Melanson D. Electroencephalography, magnetic resonance imaging and pathology in patients treated surgically for temporal lobe epilepsy. Can J Neurol Sci 1991;18:577-579.

19. Feindel W, Rasmussen T. Temporal lobectomy with amygdalectomy and minimal hippocampal resection: review of 100 cases. Can J Neurol Sci 1991;18:603-605.

20. Gloor P, Olivier A, Quesney LF, et al. The role of limbic system in experiential phenomena of temporal lobe epilepsy. Ann Neurol 1982;12:129-144.

21. Babb TL, Brown WJ. Pathological findings in epilepsy. In: Engel J Jr, ed. Surgical treatment of the epilepsies. New York: Raven Press, 1987:511-540.

22. Hudson LP, Munoz DG, McLachlan RS, et al. Amygdalar sclerosis in temporal lobe epilepsy [abstract]. Neurology 1992;42(suppl 3):400.

23. Cendes F, Andermann F, Gloor P, et al. Mesial temporal atrophy: cause or consequence of repeated seizures? Evidence from computerized MRI volumetric study [abstract]. Can J Neurol Sci 1992;9:266.

24. Gloor P. Role of amygdala in temporal lobe epilepsy. In: Eggleton GP, ed. The amygdala: neurobiological aspects of emotion, memory, and mental dysfunction. New York: Wiley-Liss, 1992:505-538. 


\section{Neurology}

Early childhood prolonged febrile convulsions, atrophy and sclerosis of mesial structures, and temporal lobe epilepsy: An MRI volumetric study

F. Cendes, F. Andermann, F. Dubeau, et al.

Neurology 1993;43;1083

DOI 10.1212/WNL.43.6.1083

This information is current as of June 1, 1993

Updated Information \& Services

Citations

Permissions \& Licensing

Reprints including high resolution figures, can be found at: http://n.neurology.org/content/43/6/1083.full

This article has been cited by 29 HighWire-hosted articles: http://n.neurology.org/content/43/6/1083.full\#\#otherarticles

Information about reproducing this article in parts (figures,tables) or in its entirety can be found online at:

http://www.neurology.org/about/about_the_journal\#permissions

Information about ordering reprints can be found online:

http://n.neurology.org/subscribers/advertise

Neurology $®$ is the official journal of the American Academy of Neurology. Published continuously since 1951, it is now a weekly with 48 issues per year. Copyright (C) 1993 by the American Academy of Neurology. All rights reserved. Print ISSN: 0028-3878. Online ISSN: 1526-632X.

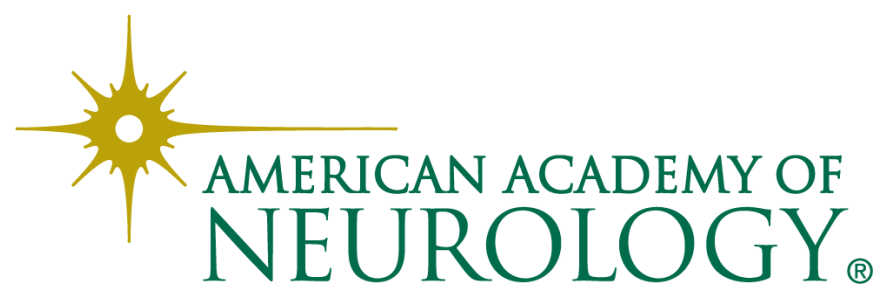

